Research Article

\title{
Influence of Upper Seam Extraction on Abutment Pressure Distribution during Lower Seam Extraction in Deep Mining
}

\author{
Feng Wang $\mathbb{D},{ }^{1,2}$ Zeqi Jie, ${ }^{1}$ Bo Ma $\mathbb{D},{ }^{1}$ Weihao Zhu, ${ }^{1}$ and Tong Chen ${ }^{1}$ \\ ${ }^{1}$ College of Energy and Mining Engineering, Shandong University of Science and Technology, Qingdao, Shandong 266590, China \\ ${ }^{2}$ State Key Laboratory of Mining Disaster Prevention and Control Co-Founded By Shandong Province and the Ministry \\ of Science and Technology, Shandong University of Science and Technology, Qingdao, Shandong 266590, China
}

Correspondence should be addressed to Bo Ma; 2415318655@qq.com

Received 30 August 2021; Accepted 27 September 2021; Published 13 October 2021

Academic Editor: Zetian Zhang

Copyright $\odot 2021$ Feng Wang et al. This is an open access article distributed under the Creative Commons Attribution License, which permits unrestricted use, distribution, and reproduction in any medium, provided the original work is properly cited.

\begin{abstract}
Pressure-relief coal mining provides an effective way to decrease stress concentration in deep mining and ensures mining safety. However, there is currently a lack of research and field verification on the pressure-relief efficiency and influencing factors during upper seam extraction on the lower seam. In order to make up for this deficiency, in this study, field measurements were conducted in panel Y485, which has a maximum depth of $1030 \mathrm{~m}$ and is partially under the goaf of the upper $5^{\#}$ seam in the Tangshan coal mine, China, and evolution of advanced abutment pressure was analyzed. Numerical simulations were conducted to study of influence of key strata on advanced abutment pressure. Influence mechanisms of the upper seam extraction on the advanced abutment pressure distribution during lower seam extraction were revealed. The results indicate that the distribution of advanced abutment stress is influenced by the key strata in the overlying strata. The key strata above the upper coal seam were fractured due to the upper coal seam mining, and the advanced abutment stress was only influenced by the key strata between the two seams during lower coal seam mining. When key strata were present between two seams, the extraction of the lower seam still faces potential dynamic disasters after the extraction of the upper seam. In this case, it would be necessary to fracture the key strata between the two seams in advance for the purpose of mining safety. Key strata in the overlying strata of the $5^{\#}$ seam were fractured during extraction, and advanced abutment pressure was only influenced by the key strata located between the two mined seams. The influence distance of advanced abutment pressure in panel Y485 decreased from $73 \mathrm{~m}$ to $38 \mathrm{~m}$, and the distance between the peak advanced abutment pressure and the panel decreased from $29 \mathrm{~m}$ to $20.5 \mathrm{~m}$, achieving a pronounced pressure-relief effect.
\end{abstract}

\section{Introduction}

Shallow coal resources are gradually exhausted, causing coal mining both in China and abroad to mine deeper and deeper to meet the growing energy demands. In China, the depth of underground mining is increasing at an average rate of 8 to $12 \mathrm{~m}$ per year. There are a total of $47 \mathrm{coal}$ mines nationwide, where the mining depth has exceeded $1,000 \mathrm{~m}$, with an average depth of $1,086 \mathrm{~m}$ and a maximum of $1,501 \mathrm{~m}$ [1]. Meanwhile, more and more coal mines will be threatened by the severe mining-induced stress concentration in deep mining [2-5]. Dynamic disasters such as rock burst $[6,7]$, coal and gas outburst $[8,9]$, and coal pillars failure [10] severely threaten the efficiency and security of coal exploitation. For example, the maximum mining depth in the Tangshan coal mine in the Kailuan Group located in Hebei Province, China, is $1,050 \mathrm{~m}$. Since the first reported rock burst that occurred on June 7, 1964, in the panel 2151 of the $5^{\#}$ seam, rock bursts have become more and more serious and frequent with the increased mining depth, posing the foremost threat to mining safety. A total of 90 rock bursts have occurred in the Tangshan coal mine up until now, mostly in the panels with a burial depth below $600 \mathrm{~m}$.

The pressure-relief mining provides an effective way to realize safe mining in a deep coal mine. According to the sequence used for mining coal seams, pressure-relief mining can be classified into two processes. The first is to mine the upper seam before the lower seam; and the second is to mine 
the lower seam before the upper seam. Given the mininginduced strata movement $[11,12]$ and pressure-relief [13-16] in the overlying strata, it is a widely adopted practice to mine the lower coal seam to release the pressure of the upper seam [17]. Several studies have been conducted on the stress distribution in the floor strata of coal seam: Suchowerska et al. [18, 19] simulated the distribution laws of horizontal and vertical stress in strata underlying a seam extracted using the longwall method. Zhang et al. [20] and Yang et al. $[21,22]$ studied the evolution law of floor stress during the mining process of the upper seam. However, none of the above literatures had taken into account the extraction of the lower seam panel after the upper seam was excavated, and there is a lack of research and field verification on the pressure-relief efficiency and influencing factors on the distribution of the advanced abutment pressure during the lower seam mining process.

The evolution of mining-induced stress is closely related to strata movement and deformation, especially the key strata in the overlying strata [23]. However, there are few studies that have explored the influence of key strata on the pressure-relief efficiency of the lower seam after the extraction of the upper seam. In order to make up for this deficiency, in this study, field measurements were conducted in panel Y485, which has a maximum depth of $1030 \mathrm{~m}$ and is partially under the goaf of the upper $5^{\#}$ seam in the Tangshan coal mine, China, and evolution of advanced abutment pressure was analyzed. Numerical simulations were conducted to study the influence of key strata on advanced abutment pressure. Influence mechanisms of the upper seam extraction on the advanced abutment pressure distribution during lower seam extraction were revealed.

\section{Field Observations}

2.1. Site Description. Panel Y485 is $150 \mathrm{~m}$ wide and $775 \mathrm{~m}$ long, and the average thickness of the $9^{\#}$ seam is $9.8 \mathrm{~m}$. The depth of the seam ranges from $800 \mathrm{~m}$ to $1,030 \mathrm{~m}$. Panel Y485 is adjacent to the goaf of panel Y486 in the south, and the northern area of Y 485 panel is the $9^{\#}$ seam. The $5^{\#}$ seam is located in the roof of the $9^{\#}$ seam, and the average vertical distance between the two seams is $35 \mathrm{~m}$. Panels 8455, $\mathrm{T}_{1} 451$, $\mathrm{T}_{1} 452, \mathrm{~T}_{1} 453$, and $\mathrm{T}_{1} 454$ operated in the $5^{\#}$ seam separately ended their mining in 1998, 2004, 2007, 2009, and 2010, respectively. The average mining height of the $5^{\#}$ seam panel is $3.5 \mathrm{~m}$, as shown in Figure 1 .

2.2. Identification of Key Strata. Key strata theory in strata control was proposed by Qian et al. in 1996 [23]. It provides a theoretical basis for understanding the movement of overburden structure and its impact on strata behavior. According to this theory, the stratum that controls the movement of the overburden strata is defined as the key stratum; if it controls all of the movement of the overburden, it is defined as the primary key stratum; if only partial movement is controlled, it is called key stratum. There may be more than one key stratum in the overburden strata; however, there is only one primary key stratum. According to the identification scheme of key strata [24], there are a total of six key strata in the J-9 borehole within the overlying strata of the $9^{\#}$ seam, as shown in Figure 2. One key stratum exists between the $5^{\#}$ and $9^{\#}$ seams. The vertical distance between key stratum and $9^{\#}$ seam is $8.5 \mathrm{~m}$, which is shown in Figure 2.

2.3. Methods and Monitoring Station. Two monitoring stations were planned in panel Y485 to analyze the influence of the extraction of the $5^{\#}$ seam on advanced abutment pressure during the advance of panel Y485. The $1^{\#}$ monitoring station was installed under the $5^{\#}$ seam, $150 \mathrm{~m}$ away from the openoff cut of panel Y485, while the $2^{\#}$ monitoring station was arranged under the goaf of the $5^{\#}$ seam, $380 \mathrm{~m}$ away from the open-off cut of panel Y485, as shown in Figures 1 and 3. In order to protect the advanced abutment pressure from being influenced by the lateral abutment pressure of panel Y486, the $2^{\#}$ monitoring station was installed on the ventilation roadway side.

Three borehole stress meters at intervals of $5 \mathrm{~m}$ were separately arranged within the monitoring station of each group, with a drilling length of $10 \mathrm{~m}$ and a drilling diameter of $\Phi 70 \mathrm{~mm}$. The distance between the borehole and the floor of roadway is $2.0 \mathrm{~m}$. The pressure sensors in the transportation roadway were connected into the network via telecommunication cables, while the data were synchronously displayed and stored in the computer on the ground. The digital pressure meters in the ventilation roadway were adopted in order to display and store the stress monitoring via an interior SD card, while the data were regularly collected through a handheld infrared collector. The schematic diagram of the stress monitoring system is shown as Figure 3.

\section{Results}

After continuous monitoring for half a year, several of the pressure meters used to monitor advanced abutment pressure failed because of the collapse of the borehole wall. During the final analysis, these borehole data were ignored. This paper separately selected one of the borehole stress meters from $1^{\#}$ and $2^{\#}$ monitoring stations for analysis. Given that the data monitored by pressure sensors were variable quantities of advanced abutment pressure during the mining process, it was difficult to compare the original monitoring data with each other; a normalization processing was performed for the variation results of advanced abutment pressure obtained from the original monitoring, as shown in Figure 4.

(1) When the panel was located in the region of the $1^{\#}$ monitoring station under the $5^{\#}$ seam, the overburden strata were within the in situ stress zone and were not disturbed by the extraction of the upper seam. Under the influence of the advanced abutment pressure of panel Y485, the distance between the peak advanced abutment pressure and the panel was $29 \mathrm{~m}$, and the influence distance of advanced abutment pressure was $73 \mathrm{~m}$. 


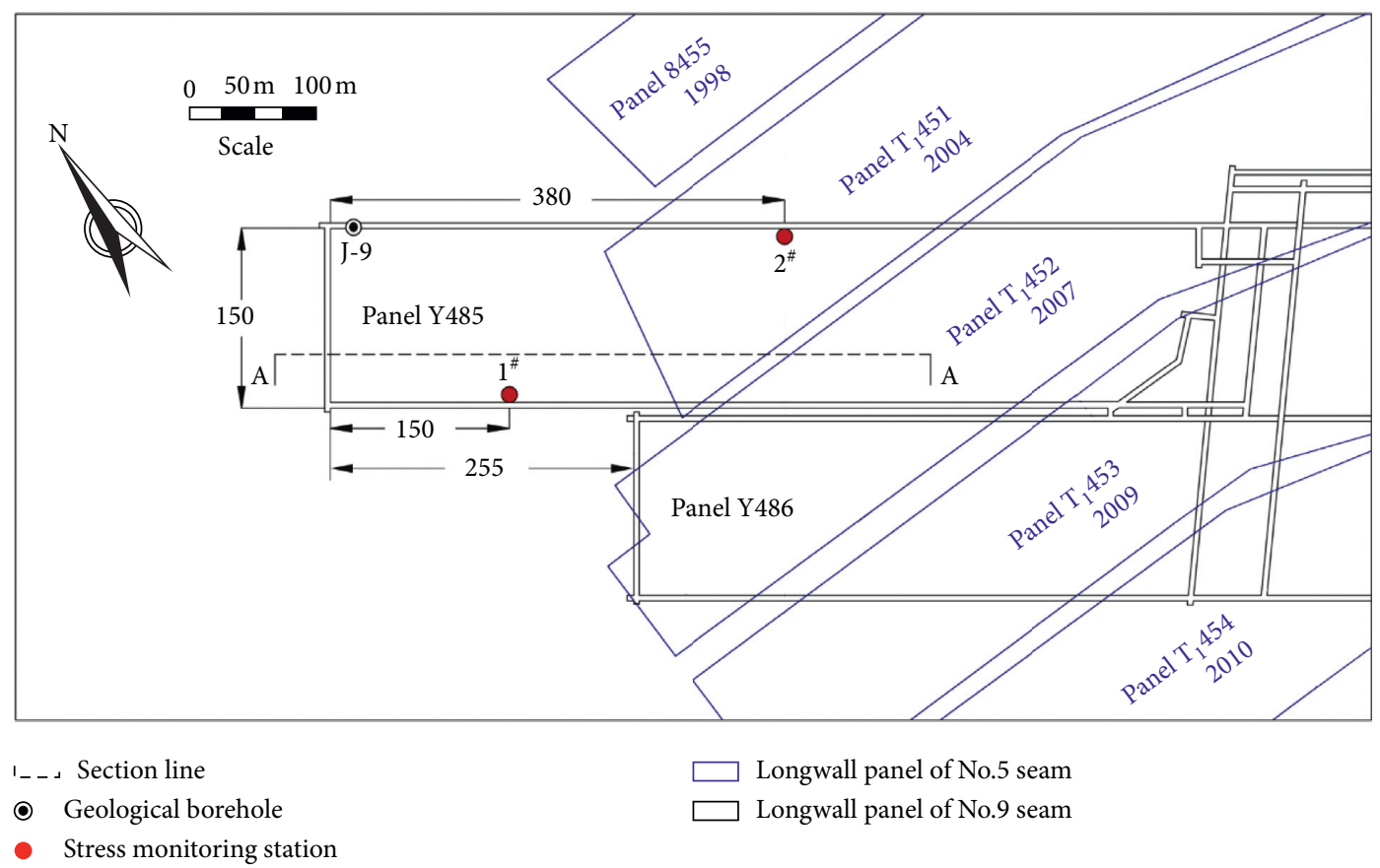

Figure 1: Layout of panel Y485.

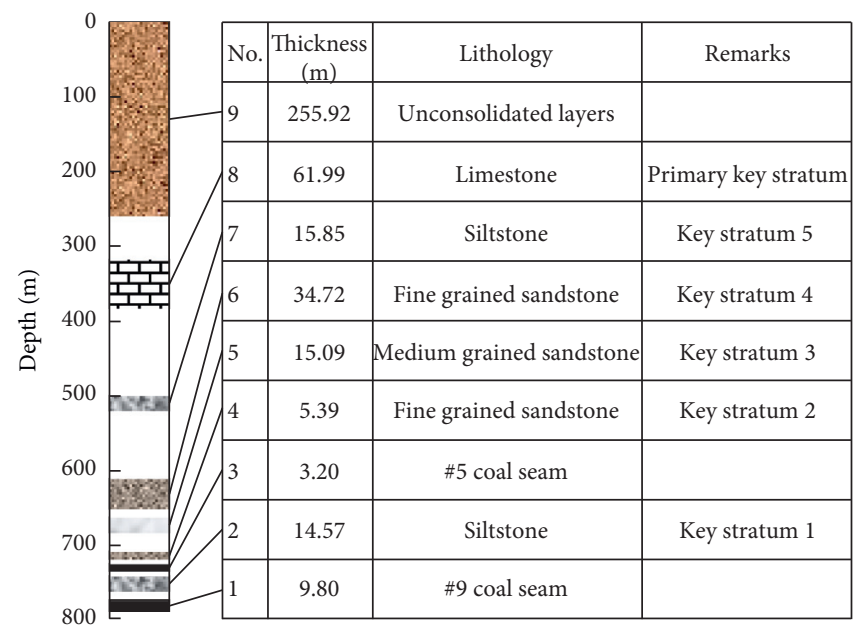

FIGURE 2: Identification results of key strata in J-9 borehole.

(2) When the panel was located in the region of the $2^{\#}$ monitoring station under the goaf of the $5^{\#}$ seam, the distance between the peak advanced abutment pressure and the panel was $20.5 \mathrm{~m}$. Unlike the distribution law of advanced abutment pressure from the $1^{\#}$ monitoring station, the advanced abutment pressure of the $2^{\#}$ monitoring station quickly decreased to a stable state after reaching the peak value. When this occurred, the influence distance of advanced abutment pressure of the panel was only $38 \mathrm{~m}$. The results indicate that a relatively large pressure-relief region appeared under the goaf, as shown in Figure 4.

(3) Therefore, after the extraction of the $5 \#$ seam, the distance between the peak advanced abutment pressure and the panel, as well as the influence distance of the advanced abutment pressure, clearly decreased during the exaction of panel Y485 located under the pressure-relief region of the goaf of the $5 \#$ seam, creating pronounced pressure-relief efficiency.

\section{Discussions}

4.1. Pressure-Relief Mechanism during Mining of Lower Seam under the Goaf of Upper Seam. The distribution of advanced abutment stress is influenced by the key strata in the overlying strata. Before the first fracturing of the key strata, the peak advanced abutment pressure and the influence distance of advanced abutment pressure gradually increase to the maximum value during the mining length increased along the panel. 


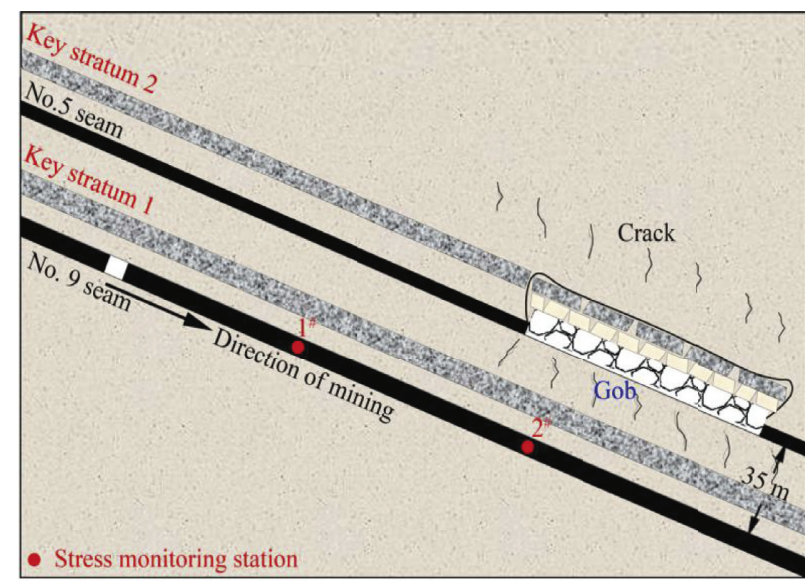

(a)

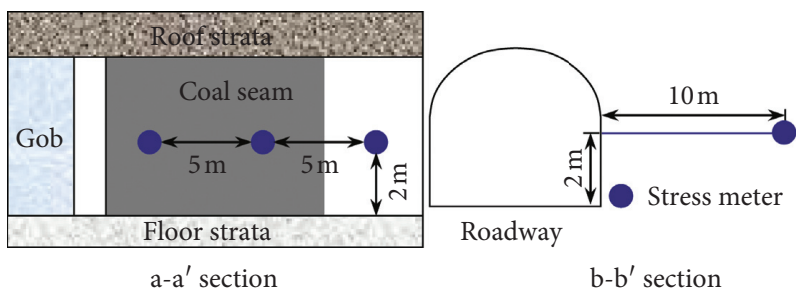

(c)

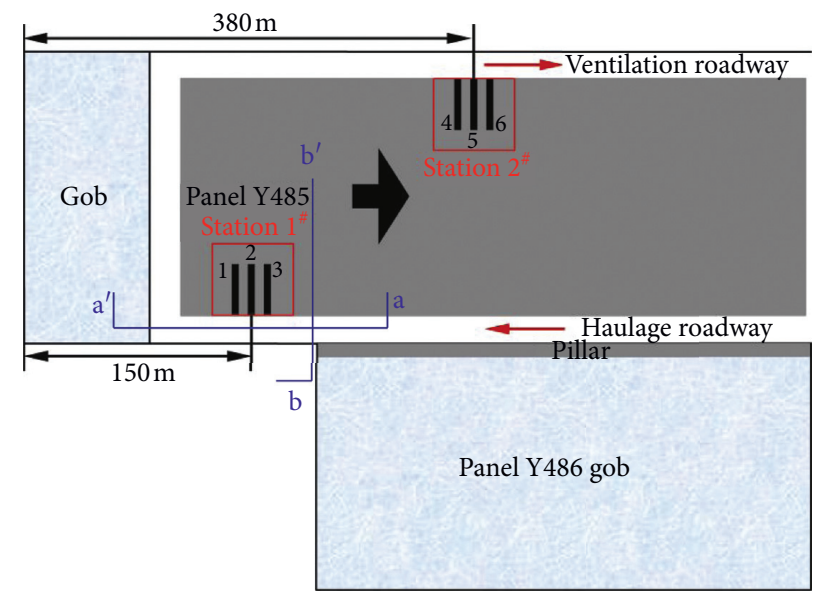

$\longleftarrow$ Section line

Borehole

(b)
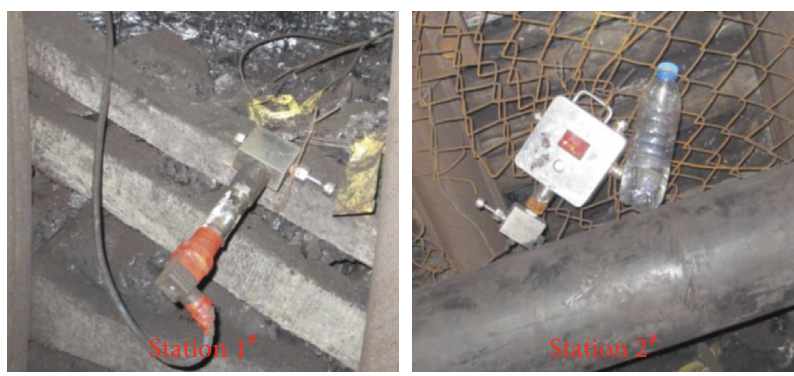

(d)

FiguRE 3: Installation of borehole stress meters. (a) Section location of stress monitoring stations. (b) Planar location of stress monitoring stations. (c) Layout of borehole stress meters; (d) borehole stress meters.

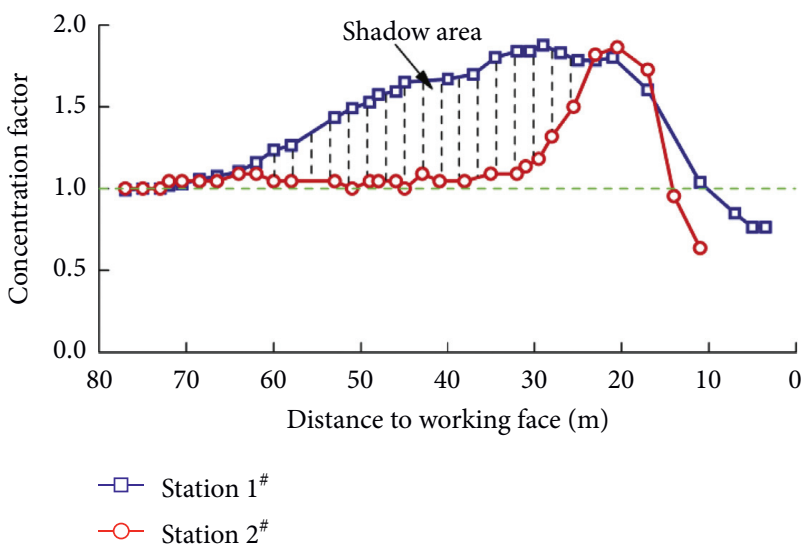

Figure 4: Evolution of advanced abutment pressure.

During the periodic weighting of key strata, the peak advanced abutment pressure significantly decreases, but the influence distance of the advanced abutment pressure remains constant. After that, the peak advanced abutment pressure value has a periodical variation along with the periodic weighting of the key strata; however, the peak advanced abutment pressure during the periodic weighting is clearly less than the periodic weighting during the first fracturing of the key strata [25].
The influence of key strata on the advanced abutment pressure distribution is primarily influenced by the thickness of key strata and distance between key strata and the seam. On the basis of comparing and analyzing the distribution of advanced abutment pressure differences with or without key strata, Guo [26] systematically studied the evolution of the advanced abutment pressure influenced by the thickness of key strata and the distance between key strata and the seam. He concluded that the coefficient of influence of key strata on advanced abutment pressure of the panel is approximately equivalent to the binary linear relation:

$$
\delta=-0 \cdot 00292 h+0 \cdot 00332 H+0 \cdot 34228,
$$

wherein $\delta$ is the coefficient of influence of key stratum on the advanced abutment pressure of the panel, $h$ is the distance between key stratum and the seam, and $H$ is the thickness of key stratum.

As shown in equation (1), the influence of key strata on the advanced abutment pressure of the panel gradually increases with an increase of thickness of key strata and a decrease of distance between key strata and the seam. The influence coefficients of the six key strata in Figure 2 on the advanced abutment pressure of panel Y485 calculated according to equation (1) are provided in Table 1. According to the influence of key strata on the advanced abutment 
TABLE 1: Coefficients of influence of the key strata on advanced abutment pressure of panel Y485.

\begin{tabular}{lccc}
\hline No. & Distance to No. 9 seam $(\mathrm{m})$ & Thickness $(\mathrm{m})$ & Coefficient of influence $(\delta)$ \\
\hline Key stratum 1 & 8.49 & 14.57 & 0.37 \\
Key stratum 2 & 47.26 & 5.39 & 0.22 \\
Key stratum 3 & 96.64 & 15.09 & 0.10 \\
Key stratum 4 & 121.74 & 34.72 & 0.10 \\
Key stratum 5 & 253.65 & 15.85 & -0.35 \\
Primary key stratum & 388.85 & 61.99 & -0.59 \\
\hline
\end{tabular}

pressure, when $\delta<0.05$, the advanced abutment pressure of the panel is not influenced by key strata; when $\delta>0.1$, the advanced abutment pressure is significantly influenced by key strata; when $0.05<\delta<0.1$, the advanced abutment pressure of the panel is influenced by key strata, but the influence is relatively insignificant [11]. Thus, during the extraction of panel Y485, key strata 1 and 2 are significantly influencing advanced abutment pressure; key strata 3 and 4 also influence the advanced abutment pressure, but only in a relatively insignificant manner; the other key strata do not influence the advanced abutment pressure of the panel.

Concerning the influence of the key strata, the relations among the influence distance of advanced abutment pressure, the thickness of the key strata, and the distance between the key strata and corresponding seam meet the requirements of equation (2) [26]. On the premise of the influence of key strata, the influence distance of the advanced abutment pressure will increase with the thickness and the distance. The influence distance of advanced abutment pressure is calculated according to equation (2) under the influence of the key strata 1 and 2, as shown in Table 2 . Therefore, the influence distance of advanced abutment pressure is $47.1 \mathrm{~m}$ under the influence of key strata 1 , while the distance is $69.7 \mathrm{~m}$ under the influence of key strata 2 . The results are generally consistent with field measurements.

$$
L=0 \cdot 781 h+0 \cdot 96939 H+26 \cdot 334,
$$

wherein $L$ is the influence distance of advanced abutment pressure under the influence of key strata, $h$ is the distance between key strata and seam, and $H$ is the thickness of key strata.

The distribution of advanced abutment pressure is both influenced by key strata 1 and 2 during the extraction of the panel Y485. The advanced abutment pressure in the area of the $1^{\#}$ monitoring station is influenced by key strata 1 and 2 . On account of key stratum 2 having been fully fractured due to the supercritical extraction of the $5^{\#}$ seam, the advanced abutment pressure in the area of the $2^{\#}$ monitoring station under the goaf of the $5^{\#}$ seam is only influenced by key stratum 1 located between the two seams. Therefore, the influence distance of advanced abutment pressure and the distance between the peak advanced abutment pressure and panel have both been significantly decreased, creating pronounced pressure-relief efficiency.

In summary, the root cause for pressure-relief during the mining process in the lower seam after the extraction of the upper seam is the fracturing of the key strata in the overlying strata. The overlying key strata are fractured because of the extraction of the upper seam. When the lower seam located under the goaf of the upper seam is being mined, the advanced abutment pressure in the lower panel is only influenced by the key strata between the two seams and is no longer influenced by the key strata located within the overlying strata of the upper seam. Under the influence of the key strata between the two seams, the influence distance of advanced abutment pressure in the panel of the lower seam and the distance between the peak advanced abutment pressure and the panel are eventually reduced.

\subsection{Numerical Study of Influence of Key Strata on Advanced} Abutment Pressure. After the extraction of the upper seam, the pressure-relief efficiency of the panel in the lower seam was influenced not only by factors such as burial depth of seam, dip angle of seam, mining height of the panel, and distance between two seams $[27,28]$, but also by the key strata located in the overlying strata, particularly the key strata between the two seams. UDEC ${ }^{2 \mathrm{D}}$ [29] was used to simulate the influence of the key strata between two seams on the advanced abutment pressure distribution in the lower seam panel after the extraction of the upper seam.

The numerical models were built as shown in Figure 5. The width and height of model were $2000 \mathrm{~m}$ and $300 \mathrm{~m}$, respectively. In Model A, there was one key stratum with a thickness of $20 \mathrm{~m}$ between two seams. In contrast, Model B was built without any key stratum between two seams, by replacing the $20 \mathrm{~m}$ thick key strata in Model A with 10 layers of mudstone strata, each with an average thickness of $2 \mathrm{~m}$. The thicknesses of the upper and lower seams were both $3 \mathrm{~m}$, and the distance between the two seams was $35 \mathrm{~m}$. During the numerical simulation, the panel of the upper seam was extracted first at $40 \mathrm{~m}$ intervals, and the mining width was varied from $40 \mathrm{~m}$ to $400 \mathrm{~m}$ (left border at $x=800 \mathrm{~m}$ ). The starting boundary of the panel in the lower seam was the same with that of the upper seam. The extraction of lower seam was $40 \mathrm{~m}$ for each time period, and the accumulated width is $400 \mathrm{~m}$. The left and right boundaries of the model were fixed in the horizontal direction, while the bottom boundary was fixed in the vertical direction. The elasticplastic model and the Mohr-Coulomb failure criterion were applied to the model. Table 3 shows the mechanical parameters of rock strata during the numerical simulation.

During the initial elastic equilibrium, the in situ stress of the lower seam in both models was $6.34 \mathrm{MPa}$. The mininginduced stress in the seam was redistributed during the mining process. The mining-induced vertical stress distribution in the lower seam and the relationships between the peak stress concentration factors of advanced abutment pressure and mining length are, respectively, shown in Figure 6. 
TABLE 2: Influence distance of advanced abutment pressure under the influence of key strata 1 and 2.

\begin{tabular}{lccc}
\hline No. & Distance to No. 9 seam $(\mathrm{m})$ & Thickness $(\mathrm{m})$ & Influence distance of the advanced abutment pressure $(\mathrm{m})$ \\
\hline Key stratum 1 & 8.49 & 14.57 & 47.1 \\
Key stratum 2 & 47.26 & 5.39 & 69.7 \\
\hline
\end{tabular}

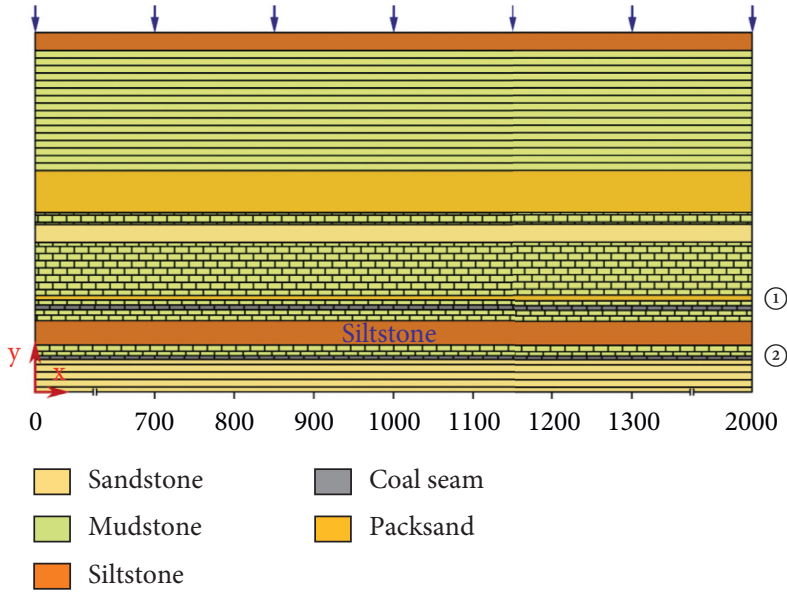

(a)

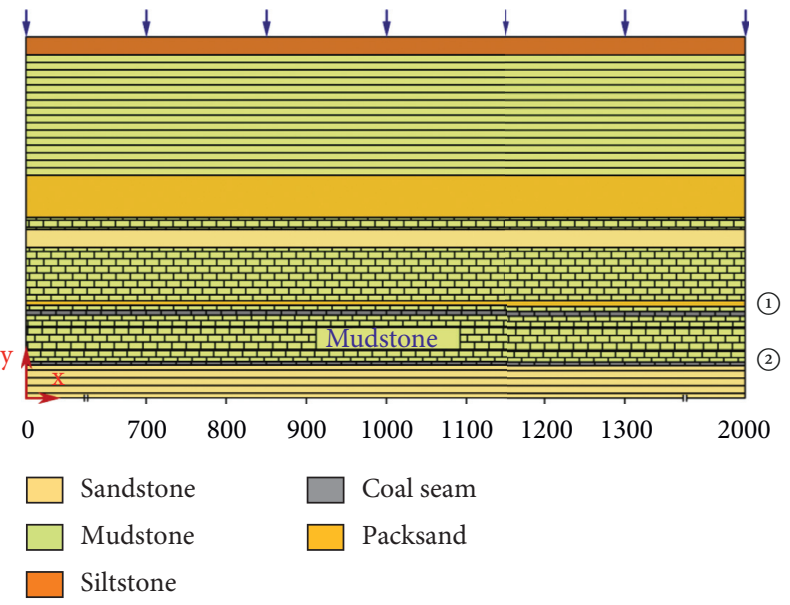

(b)

Figure 5: Numerical simulation. (a) Model A (presence of siltstone key strata between two seams). (b) Model B (absence of key strata between two seams). (1) Upper seam. (2) Lower seam.

TABLE 3: Mechanical parameters of rock layer in the numerical model.

\begin{tabular}{lcccccc}
\hline Rock layer & Density $\left(\mathrm{kg} / \mathrm{m}^{3}\right)$ & Young's modulus $(\mathrm{GPa})$ & Poisson ratio & Friction angle $\left(^{\circ}\right)$ & Tensile strength $(\mathrm{MPa})$ & Cohesion $(\mathrm{MPa})$ \\
\hline Sandstone & 2690 & 12.5 & 0.22 & 32 & 6.5 & 10.5 \\
Siltstone & 2650 & 10.0 & 0.22 & 36 & 5.5 & 7.5 \\
Pack sand & 2740 & 14.5 & 0.20 & 36 & 3.5 & 12.5 \\
Mudstone & 2560 & 8.0 & 0.28 & 28 & 2.5 & 3.5 \\
Coal seam & 1340 & 4.5 & 0.32 & 20 & 3.6 \\
\hline
\end{tabular}

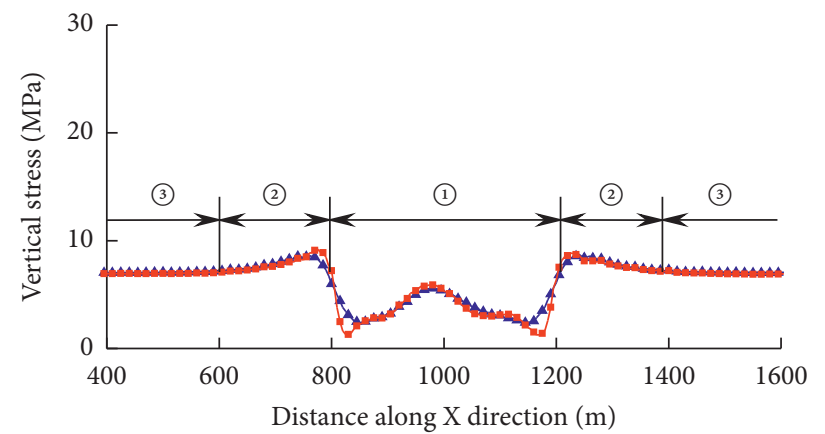

(1) Stress decreased zone

(2) Stress increased zone

(3) Original stress zone

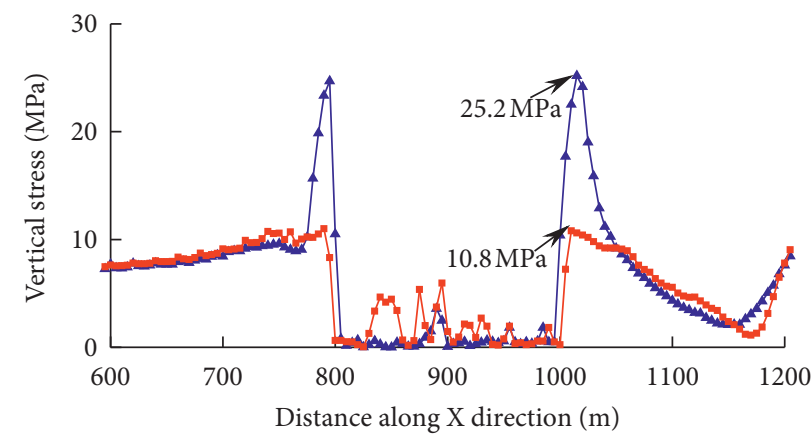

— Model A

- Model B

(a)

(b)

Figure 6: Continued. 


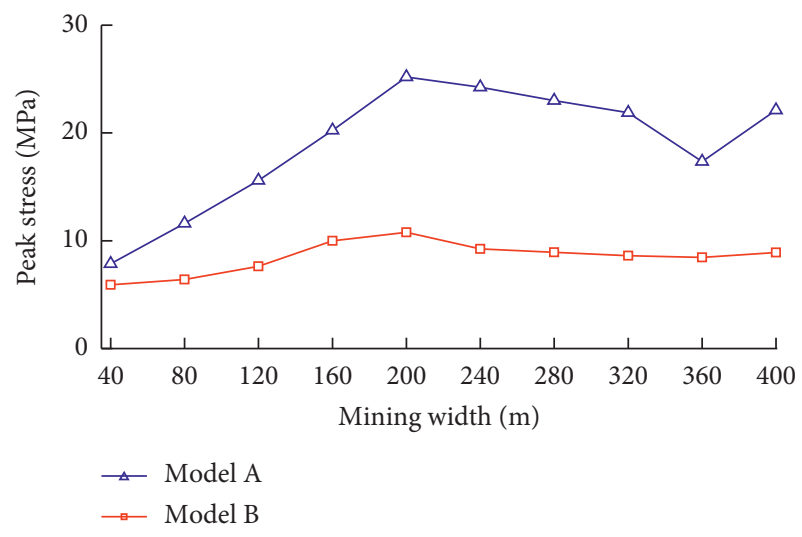

(c)

Figure 6: Mining-induced stress distribution. (a) Vertical stress distribution of the lower seam after the extraction of the upper seam. (b) Vertical stress distribution when the length of the panel was $200 \mathrm{~m}$. (c) Variation of peak stress concentration factors of the advanced abutment pressure in lower seam.

(1) Figure 6(a) shows the mining-induced vertical stress distribution after extraction of the upper seam. Stress distribution in the lower seam can be divided into three zones: (1) the stress decreased zone, (2) the stress increased zone, and (3) the original stress zone [21]. The two models are generally consistent in terms of the pressure-relief efficiency for the lower seam after the upper seam was mined.

(2) After the extraction of the upper seam, when the mining width of lower seam panel was $200 \mathrm{~m}$ (Figure 6(b)), the peak vertical stress in Model A was almost 2.3 times of Model B. The peak stress concentration factors were 3.97 and 1.70 , respectively. Obviously, although the panel was within the stressrelief zone of the upper seam, a severe stress concentration was still generated during the extraction of the panel in the lower seam when a $20 \mathrm{~m}$ thickrigid key stratum was present.

(3) As shown in Figure 6(c), the peak stress concentration factors of advanced abutment pressure increased with the mining width and were at a maximum at a mining width of $200 \mathrm{~m}$ in both Models $\mathrm{A}$ and $\mathrm{B}$. In the presence of the thick-rigid key strata (Model A), the peak stress concentration factors decreased with the mining width; however, in the absence of key strata (Model B), the peak stress concentration factors appeared to stabilize with an increase mining width. Generally, the peak stress concentration factors were greater in Model A than those in Model B.

Therefore, when there is no key stratum between two seams, mining of the upper seam to fracture the key strata located in the overlying strata can cause an obvious pressurerelief within the lower seam. When there exists a key stratum between two seams, moderate satisfactory pressure-relief efficiency can be achieved. However, when there are thick-rigid key strata between two seams, the panel in the lower seam during the mining process has the potential of dynamic disasters after the extraction of the upper seam. In order to avoid the threats of dynamic disasters caused by the mining-induced stress concentration during the mining process in deep mining, it is necessary to fracture the key strata between seams in advance $[7,30]$ to decrease the influence of the key strata on the advanced abutment pressure within the panel in the lower seam.

\section{Conclusions}

(1) The key strata were fractured due to the supercritical extraction of the $5^{\#}$ seam in the Tangshan coal mine. The advanced abutment pressure in panel Y485 located in the $9^{\#}$ seam was only influenced by the key strata between the two seams and was no longer influenced by the key strata within the overlying strata of the $5^{\#}$ seam. Therefore, the influence distance of the advanced abutment pressure in panel Y 485 decreased from $73 \mathrm{~m}$ to $38 \mathrm{~m}$, and the distance between the peak advanced abutment pressure and the panel decreased from $29 \mathrm{~m}$ to $20.5 \mathrm{~m}$.

(2) Numerical simulation indicated that when thickrigid key strata are present between two seams, the extraction of the lower seam still faces potential dynamic disasters after the extraction of the upper seam. In this case, it is necessary to fracture the key strata between the seams in advance for the purpose of mining safety.

(3) For deep mining, the pressure-relief efficiency in the lower seam depends on the key strata located in the overlying strata, particularly the key strata between two coal seams. Therefore, the key strata must be taken into consideration when the upper seam is selected to release the mining-induced stress of the lower seam. 


\section{Data Availability}

All data used to support the findings of this study are included within the article, and there are no restrictions on data access.

\section{Conflicts of Interest}

The authors declare no conflicts of interest.

\section{Acknowledgments}

This research was supported by the China Postdoctoral Science Foundation (no. 2020M682208) and Elite talent project of SDUST.

\section{References}

[1] M.-C. He, H.-P. Xie, S.-P. Peng, and Y.-D. Jiang, "Study on rock mechanics in deep mining engineering," Chinese Journal of Rock Mechanics and Engineering, vol. 24, no. 16, pp. 2803-2813, 2005.

[2] H.-P. Xie, H.-W. Zhou, D.-J. Xue, H.-W. Wang, R. Zhang, and F. Gao, "Research and consideration on deep coal mining and critical mining depth," Journal of China Coal Society, vol. 37, no. 4, pp. 535-542, 2012.

[3] J.-H. Liu, F.-X. Jiang, N.-G. Wang, Z.-G. Zhang, and R.-X. Zhang, "Survey on abutment pressure distribution of fully mechanized caving face in extra-thick coal seam of deep shaft," Journal of China Coal Society, vol. 36, no. 1, pp. 18-22, 2011.

[4] H. Jing, J. Wu, Q. Yin, and K. Wang, "Deformation and failure characteristics of anchorage structure of surrounding rock in deep roadway," International Journal of Mining Science and Technology, vol. 30, no. 5, pp. 593-604, 2020.

[5] N. Zhang, N. Zhang, C. Han, D. Qian, and F. Xue, "Borehole stress monitoring analysis on advanced abutment pressure induced by Longwall mining," Arabian Journal of Geosciences, vol. 7, no. 2, pp. 457-463, 2014.

[6] M. Ghorbani, K. Shahriar, M. Sharifzadeh, and R. Masoudi, "A critical review on the developments of rock support systems in high stress ground conditions," International Journal of Mining Science and Technology, vol. 30, no. 5, pp. 555-572, 2020.

[7] P. Konicek, K. Soucek, L. Stas, and R. Singh, "Long-hole destress blasting for rockburst control during deep underground coal mining," International Journal of Rock Mechanics and Mining Sciences, vol. 61, pp. 141-153, 2013.

[8] A. J. Hargraves, "Instantaneous outbursts of coal and gas a review," Proceedings - Australasian Institute of Mining and Metallurgy, vol. 285, no. 3, pp. 1-37, 1983.

[9] B. B. Beamish and P. J. Crosdale, "Instantaneous outbursts in underground coal mines an overview and association with coal type," International Journal of Coal Geology, vol. 35, no. 1-4, pp. 27-55, 1998.

[10] Q. Huang, J. Du, J. Chen, and Y. He, "Coupling control on pillar stress concentration and surface cracks in shallow multiseam mining," International Journal of Mining Science and Technology, vol. 31, no. 1, pp. 95-101, 2021.

[11] M.-G. Qian, P.-W. Shi, and J.-L. Xu, Mine Pressure and Ground Control, China University of Mining and Technology Press, Xuzhou, China, 2010.
[12] F. Wang, B.-Y. Jiang, S.-J. Chen, and M.-Z. Ren, "Surface collapse control under thick unconsolidated layers by backfilling strip mining in coal mines," International Journal of Rock Mechanics and Mining Sciences, vol. 113, pp. 267-277, 2019.

[13] P. Konicek, J. Schreiber, and L. Nazarova, "Volumetric changes in the focal areas of seismic events corresponding to destress blasting," International Journal of Mining Science and Technology, vol. 29, no. 4, pp. 541-547, 2019.

[14] J. Zhang, W. Yang, B. Lin, J. Zhang, and M. Wang, "Strata movement and stress evolution when mining two overlapping panels affected by hard stratum," International Journal of Mining Science and Technology, vol. 29, no. 5, pp. 691-699, 2019.

[15] H. Yavuz, "An estimation method for cover pressure re-establishment distance and pressure distribution in the goaf of longwall coal mines," International Journal of Rock Mechanics and Mining Sciences, vol. 41, no. 2, pp. 193-205, 2004.

[16] F. Wang, J. Xu, and J. Xie, "Effects of arch structure in unconsolidated layers on fracture and failure of overlying strata," International Journal of Rock Mechanics and Mining Sciences, vol. 114, pp. 141-152, 2019.

[17] L. Yuan, "Key technique of safe mining in low permeability and methane-rich seam group," Chinese Journal of Rock Mechanics and Engineering, vol. 27, no. 7, pp. 1370-1379, 2008.

[18] A. M. Suchowerska, R. S. Merifield, and J. P. Carter, "Vertical stress changes in multi-seam mining under supercritical longwall panels," International Journal of Rock Mechanics and Mining Sciences, vol. 61, pp. 306-320, 2013.

[19] A. M. Suchowerska, J. P. Carter, and R. S. Merifield, "Horizontal stress supercritical longwall panels," International Journal of Rock Mechanics and Mining Sciences, vol. 70, pp. 241-250, 2014.

[20] M. Zhang, H. Shimada, T. Sasaoka, K. Matsui, and L. Dou, "Evolution and effect of the stress concentration and rock failure in the deep multi-seam coal mining," Environmental Earth Sciences, vol. 72, no. 3, pp. 629-643, 2014.

[21] W. Yang, B.-Q. Lin, Q. Yan, and C. Zhai, "Stress redistribution of longwall mining stope and gas control of multi-layer coal seams," International Journal of Rock Mechanics and Mining Sciences, vol. 72, pp. 8-15, 2014.

[22] W. Yang, B.-Q. Lin, Y.-A. Qu et al., "Stress evolution with time and space during mining of a coal seam," International Journal of Rock Mechanics and Mining Sciences, vol. 48, no. 7, pp. 1145-1152, 2011.

[23] M.-G. Qian, X.-X. Miao, J.-L. Xu, and X.-B. Mao, Theory of Key Stratum in Ground Control, China University of Mining and Technology Press, Xuzhou, China, 2003.

[24] J.-L. Xu and M.-G. Qian, "Method to distinguish key strata in overburden," Journal of China University of Mining and Technology, vol. 29, no. 5, pp. 463-467, 2000.

[25] H. Pu and X.-X. Miao, "Effect of key strata movement in the mining-induced overlying strata on the abutment pressure distribution in surrounding rock," Chinese Journal of Rock Mechanics and Engineering, vol. 21, no. 2, pp. 2366-2369, 2002.

[26] J.-K. Guo, "Study on the effect of the main key stratum on the advance abutment stress," M. S. Thesis, China University of Mining and Technology, Xuzhou, China, 2015.

[27] State Administration of Coal Mine Safety, Provisions Of the Prevention of Coal and Gas Outburst, Coal Industry Press, Beijing, China, 2005. 
[28] W.-B. Zhu, Study on the Instability Mechanism of Key Strata Structure in Repeat Mining of Shallow Close Distance Seams, Ph.D. Thesis, China University of Mining and Technology, Xuzhou, China, 2010.

[29] Itasca Consulting Group, UDEC User Manual, Itasca Consulting Group, Inc, Minneapolis, MN, USA, 2008.

[30] Z. Yang, C. Liu, H. Zhu, F. Xie, L. Dou, and J. Chen, "Mechanism of rock burst caused by fracture of key strata during irregular working face mining and its prevention methods," International Journal of Mining Science and Technology, vol. 29, no. 6, pp. 889-897, 2019. 